\title{
JUVENTUDE, MATERNIDADE E EVASÃO ESCOLAR: REALIZANDO UM ESTADO DA ARTE NO CATÁLOGO DE TESES E DISSERTAÇÕES DA CAPES
}

Jéssica Kurak Ponciano; Márcia Regina Canhoto de Lima; José Milton de Lima; Sérgio Luiz Gibim dos Santos

Universidade Estadual Paulista - UNESP, Programa de Pós-Graduação em Educação, Presidente Prudente, SP. E-mail: jessica.kpp22@gmail.com

\section{RESUMO}

O presente artigo, resultado de uma pesquisa empreendida no primeiro semestre do ano de 2018 , teve como objetivo realizar uma síntese integrativa dos conhecimentos produzidos acerca da relação entre a evasão escolar de jovens e a maternidade durante o período de escolarização. Esta investigação, de caráter qualitativo e quantitativo, contou com a técnica de análise documental denominada "estado da arte" ou "estado do conhecimento" das pesquisas que compõem o Catálogo de Dissertações e Teses da CAPES. A partir de uma análise preliminar, constatamos que são poucas as pesquisas brasileiras, em nível de pós-graduação, que se propuseram a investigar a temática por nós delimitada. Além disso, alguns dos trabalhos que investigaram a relação entre gravidez na adolescência, evasão escolar e juventude foram realizadas por pesquisadores da área da saúde. A síntese integrativa das pesquisas brasileiras buscou identificar como a relação entre a evasão escolar, as juventudes e a maternidade vem sendo abordada pelas diversas áreas do conhecimento.

Palavras-chave: Maternidade; Evasão Escolar; Juventudes; Estado da Arte; Sociologia da Juventude.

\section{YOUTH, MATERNITY AND SCHOOL EVASION: REALIZING A STATE OF ART IN THE CATALOG OF THESES AND DISSERTATIONS OF CAPES}

\begin{abstract}
This article, the result of a research undertaken in the first semester of 2018, aimed to make an integrative synthesis of the knowledge produced about the relationship between school dropout among young people and motherhood during the period of schooling. This research, of a qualitative and quantitative nature, counted on the documentary analysis technique called "state of the art" or "state of knowledge" of the research that compose the Catalog of Dissertations and Theses of CAPES. From a preliminary analysis, we find that few Brazilian studies, at the postgraduate level, have set out to investigate the thematic delimited by us. In addition, some of the studies that investigated the relationship between teenage pregnancy, school dropout, and youth were conducted by health researchers. The integrative synthesis of Brazilian research has sought to identify how the relationship between school dropout, youth and motherhood has been approached by the different areas of knowledge.
\end{abstract}

Keywords: Maternity; School Evasion; Youths; State of art; Sociology of Youth. 


\section{INTRODUÇÃO}

O problema da evasão escolar ainda é uma constante na sociedade brasileira. Dados extraídos do Censo Escolar de 2014 e 2015, promovido pelo Instituto Nacional de Estudos e Pesquisas Educacionais Anísio Teixeira (Inep) e Ministério da Educação, divulgados no ano de 2017, mostra que $12,9 \%$ e $12,7 \%$ dos discentes regularmente matriculados na 1 a e 2a série do Ensino Médio, respectivamente, evadiram da escola entre os anos de 2014 e 2015 (INEP, 2017). Dentre os jovens matriculados no 3 o ano do Ensino Médio, houve um índice de evasão de 6,8\%. Desta forma, todas as séries do Ensino Médio somam um total de $11,2 \%$ de estudantes evadidos em todo o país (INEP, 2017). Estes dados revelam que aproximadamente 1,3 milhão de jovens na idade entre 15 e 17 anos abandonam a escola no Ensino Médio. Além disso, o site Agência Brasil assevera que, a partir dos estudos realizados pelo IBGE e MEC, de um total de 1,3 milhão de jovens que se encontram evadidos da sala de aula, 610 mil são meninas; dentre elas, apenas $2 \%$ das adolescentes que se tornaram mães durante o Ensino Médio, continuaram seus estudos (TOKARNIA, 2016).

A relação entre a trajetória escolar, a classe social, o gênero e a gravidez na adolescência fica ainda mais evidente nos estudos de Maria Helena Favero e Regina Maria Mello (1997), que afirmam haver um consenso sobre a vinculação da trajetória de escolarização da jovem gestante e a própria gravidez (FAVERO; MELLO, 1997, p. 133). Apesar disto, as autoras também assumem a importância em investigar, com cautela, os processos educacionais das adolescente que engravidam, analisando aspectos relacionados ao abandono escolar e/ou a interrupção temporária dos estudos; de modo que a circunspecção da análise deve rimar pela consideração de outras variáveis, tais como: "a história acadêmica, o momento do processo educacional no qual ocorreu a gravidez, o valor da maternidade" (FAVERO; MELLO, 1997, p. 133), etc.

Acerca do valor da maternidade, Maria Helena Favero e Regina Maria Mello (1997) afirmam ainda que o fato de se tornar mãe pertence à uma construção hegemônica de feminilidade, de modo que a maternidade pode significar, para muitas jovens, uma aspiração e satisfação pessoal (1997, p. 133). Nesta circunstância, é possível refletir sobre a maternidade enquanto um fenômeno de "encerramento / finalização" da juventude e um marco de passagem para a vida adulta visto que, "tornarem-se" mães pode representar o desejo de serem elevadas, mais cedo, à categoria de adultas.

Acreditamos ainda que a escola contemporânea, pautada numa racionalidade neoliberal, traça e expõe as jovens mães uma perspectiva distorcida acerca da maternidade, relacionando-a à perspectiva de que cada indivíduo é responsável por suas próprias escolhas, de forma que essas "opções" ou "caminhos" a serem traçados devem direcionar o sujeito ao aperfeiçoamento pessoal, elemento que nesta racionalidade se encontra ao alcance de todos (MOREIRA; NARDI, 2009, p. 573).

O interesse em catalogar e investigar os discursos sobre evasão escolar, juventude e maternidade se deu em decorrência da multiplicidade de perspectivas acerca do fenômeno da gravidez na adolescência, bem como a relevância e o impacto deste fator sobre a vida das jovens mães, sobretudo aquelas que se encontram em idade escolar. Deste modo o objetivo dessa pesquisa foi a investigação da quantidade e dos conteúdos das pesquisas produzidas no país e compiladas no Catálogo de Dissertações e Teses da CAPES que versam sobre a temática supracitada.

\section{METODOLOGIA}

Para a realização deste "estado da arte", inicialmente, definimos alguns descritores que objetivaram direcionar as buscas por nós empreendidas. Em seguida, definimos o Catálogo de Teses e Dissertações da CAPES como o banco de dados no qual realizaríamos a nossa investigação. Após a definição dos descritores e da base de dados a ser consultada, estabelecemos como 
critério avaliar, de maneira integral, os trabalhos que apresentassem discussões que relacionam a maternidade na juventude como um elemento que se relaciona, de alguma forma, ao fenômeno da evasão escolar no Brasil.

Realizamos o levantamento das teses e dissertações catalogadas e, após esta etapa, fizemos uma leitura atenta do material produzido com o intuito de diagnosticar os objetivos das pesquisas, seus corpus, métodos de coletas de dados e análises e referenciais teóricos utilizados pelos pesquisadores para analisar os dados de forma crítica. Por fim, desenvolvemos uma tabela sintetizando os descritores utilizados, bem como o número de pesquisas encontradas à partir de cada um deles, além de uma síntese dos principais elementos subjacentes, ação motivada pela necessidade de apresentar as tendências que emergem dos temas por nós investigados.

Esta metodologia é característica de trabalhos que buscam realizar investigações na modalidade "estados da arte" e/ou "estado do conhecimento", assim como postula Joana Paulin Romanowski e Romilda Teodora Ens (2006). Na sequência, apresentaremos, de modo sintético, os resultados e a síntese sistêmica elaborada ao longo da investigação. $O$ estado da arte tem como finalidade diagnosticar temáticas relevantes, recorrentes e/ou emergentes, e apontar quais são as tipologias de pesquisas que se desenvolvem numa determinada área, bem como organizar as informações e as lacunas existentes dentro de um campo temático (ROMANOWSKI; ENS, 2006, p. 41). Deste modo, um estado da arte pode ser definido como um compilado de levantamentos do que se conhece sobre uma determinada área do conhecimento, desenvolvendo protótipos de análises de pesquisas a fim de avaliar as situações e métodos da produção do conhecimento da área observada (ROMANOWSKI; ENS, 2006, p. 41).

\section{RESULTADOS}

Ao longo de nossa pesquisa, identificamos exatamente seis produções que se dedicaram a compreender o entrelaçamento entre juventude, gravidez / maternidade e evasão escolar. A fim de explicitar os termos por nós utilizados como descritores, confeccionamos a tabela abaixo:

Tabela 1. Levantamento de Teses e Dissertações (Catálogo CAPES)

\begin{tabular}{|c|c|c|c|}
\hline $\begin{array}{l}\text { DESCRITORES UTILIZADOS NO BANCO DE } \\
\text { DADOS }\end{array}$ & $\begin{array}{l}\text { Total de Dissertações } \\
\text { e Teses encontradas }\end{array}$ & $\begin{array}{l}\text { Dissertações } \\
\text { excluídas do } \\
\text { pesquisa }\end{array}$ & $\begin{array}{l}\text { e Teses } \\
\text { corpus da }\end{array}$ \\
\hline "maternidade" AND "evasão escolar" & 10 & 6 & \\
\hline $\begin{array}{l}\text { "gravidez na adolescência" AND "evasão } \\
\text { escolar" }\end{array}$ & 19 & 14 & \\
\hline "gravidez" AND "evasão escolar" & 33 & 27 & \\
\hline "maternidade" AND "absenteísmo" & 13 & 13 & \\
\hline $\begin{array}{l}\text { "gravidez na adolescência" } \\
\text { "absenteísmo" }\end{array}$ & 0 & 0 & \\
\hline "gravidez" AND "absenteísmo" & 6 & 6 & \\
\hline
\end{tabular}

Fonte: Autores

O trabalho, da pesquisadora Carla Roberta Macedo De Sousa, intitulado "Apoio social e evasão escolar em gestantes adolescentes assistidas na estratégia de saúde da família do município de Sobral - CE", é uma dissertação de mestrado, realizada no Programa de PósGraduação em Saúde da Família da Universidade Federal do Ceará. Nesta investigação, a autora se dedicou em realizar uma descrição da natureza da relação entre o apoio social percebido e o processo de evasão escolar de jovens gestantes acompanhadas pelo programa Estratégia de Saúde da Família do município de Sobral - CE (SOUSA, 2016). O referencial teórico que subsidiou a 
análise qualitativa do objeto investigado foi a Teoria do Apoio Social (SOUSA, 2016). Como objeto de pesquisa, foram entrevistadas 20 gestantes, na faixa etária entre 14 e 19 anos, que foram atendidas, durante o seu pré-natal pela Estratégia Saúde da Família de Sobral - CE. As entrevistas foram semiestruturadas e, como resultado, observou-se que a escola não se mostrou uma instituição eficiente na oferta de apoio social, de forma que este elemento demonstrou correlação com o fenômeno da evasão escolar de jovens gestantes no município de Sobral - CE (SOUSA, 2016).

A pesquisa realizada por Iris Teresa Lafuente Avila, nomeada "A reincidência da gravidez na adolescência e a evasão escolar" é uma dissertação de mestrado, apresentada ao Programa de Pós-Graduação em Educação Escolar da UNESP de Araraquara - SP. O estudo objetivou analisar a reincidência da gravidez na adolescência correlacionada aos possíveis motivos que contribuem para o processo de evasão escolar (AVILA, 2015). Além disso, a pesquisadora buscou refletir sobre possíveis formas de reinserção das jovens mães no ambiente escolar. A investigação, de caráter qualitativo, contou com a técnica de análise documental, composto pelos questionários socioeconômicos e pela análise de diários documentais produzidos por quatro jovens, assistidas pelo Serviço Público de Psicologia de uma maternidade municipal de Araraquara - SP, no ano de 2012 (AVILA, 2015). A análise dos diários elencou diversas temáticas e, como resultado, destacaram-se as reverberações psicossociais e educacionais da gravidez e da maternidade na adolescência, sobretudo no que tange ao aspecto da reincidência da gravidez ainda na juventude (AVILA, 2015). Avila (2015) conclui ainda que as escolas das jovens investigadas não ofertavam programas de prevenção e de educação sexual que pudessem contribuir para a diminuição da evasão escolar.

A dissertação "Trajetória escolar de jovens com experiência de gravidez na adolescência" produzida por Kamila Cristiane de Oliveira Silva e apresentada ao Programa de Mestrado em Ciências e Saúde da Universidade Federal do Piauí teve como objetivo investigar a trajetória escolar de jovens que possuíam antecedentes obstétricos na adolescência. A pesquisa realizou um estudo transversal com 464 jovens que finalizaram uma gravidez no primeiro quadrimestre de 2006 (SILVA, 2011). Após a aplicação de questionários semiestruturados, a pesquisadora procedeu com análise estatística descritiva, regressão logística simples e regressão logística múltipla para a realização da análise univariada, bivariada e multivariada, respectivamente, caracterizando a investigação como uma pesquisa de caráter quantitativo (SILVA, 2011). Ao final da investigação, ficou evidente que a evasão escolar acometia, com maior frequência, as jovens que abandonavam a escola antes de engravidar pela primeira vez. Silva (2011) também correlacionou a evasão escolar aos aspectos concernentes as questões econômico financeiras das famílias das jovens mães.

O estudo denominado "As Representações Sociais da Evasão Escolar para mães adolescentes: contribuição para a Enfermagem", produzido por Maria Angélica Silveira Padilha foi uma pesquisa empreendida durante a Pós-Graduação em Enfermagem, a nível de mestrado acadêmico, na Faculdade de Enfermagem da Universidade Federal de Pelotas (PADILHA, 2011). O estudo teve como principal objetivo identificar as representações sociais da gravidez e da evasão escolar para as jovens mães. Padilha (2011) classificou o estudo como qualitativo, exploratório e descritivo, elegendo como sujeitos, cinco mães adolescentes que participaram de grupos focais, durante o mês de outubro de 2010 em um Hospital de Ensino da cidade de Pelotas-RS. Após a coleta de dados e utilizando, como referencial teórico, a Teoria das Representações Sociais, os dados foram submetidos à análise temática (PADILHA, 2011). Os resultados demonstram que as mães adolescentes que estudavam na rede pública de ensino da zona urbana, pertenciam à família de baixa renda, pouca escolaridade e a trajetória escolar era caracterizada por reprovação de um ou mais anos escolares, de forma que a evasão era justificada por elas em decorrência da gravidez (PADILHA, 2011). 
A dissertação intitulada "A valorização do desejo feminino como via de inclusão escolar da aluna grávida e puérpera: um estudo a partir da filosofia e psicanálise", produzida por Maria Cecília de Souza, no Programa de Pós-Graduação em Educação Física da Universidade Federal do Espírito Santo buscou averiguar o impacto da gravidez na adolescência de jovens mães e gestantes, alunas do ensino fundamental de uma instituição pública localizada no município de Vitória, na Grande Maruípe (SOUZA, 2014). A pesquisadora se inseriu na instituição, utilizou a modalidade de investigação denominada "pesquisa-ação", com abordagem qualitativa. Ao final da investigação, concluiu que é fundamental que haja, em instituições públicas de ensino fundamental, práticas pedagógicas que se voltem para a afetividade das alunas em período perinatal e para a necessidade de investimento do Estado em políticas educacionais de suporte à aluna grávida e puérpera (SOUZA, 2014).

A tese de doutorado, nomeada "Estratégias para o enfrentamento da evasão escolar de mães e grávidas adolescentes no município de Campos dos Goytacazes", apresentada junto ao programa de Pós-Graduação em Cognição e Linguagem do Centro de Ciências do Homem da Universidade Estadual do Norte Fluminense "Darcy Ribeiro" UENF, produzida por Karla Rangel Ribeiro, buscou verificar os motivos da evasão de adolescentes grávidas de Campos dos Goytacazes - RJ, bem como diagnosticar quais seriam as estratégias mais efetivas no sentido de buscar a garantia da permanência das jovens evadidas (RIBEIRO, 2016). A pesquisa contou com análise quali-quantitativa, os dados foram extraídos da aplicação de um questionário com questões semi-dirigidas e fechadas (obedecendo a escala de Likert), além de entrevistas estruturada, com questões de múltipla escolha. Os resultados diagnosticaram que uma das principais causas da evasão escolar se relaciona à baixa renda familiar, ao baixo nível de escolaridade dos familiares, aos aspectos psicológicos/comportamentais (ansiedade, consumo de álcool e envolvimento em episódio de bullying), à baixa motivação das estudantes evadidas e, ainda, à baixa capacidade de estímulo por parte dos docentes e direção (RIBEIRO, 2016).

\section{DISCUSSÃO}

Esta pesquisa evidenciou que muitos dos trabalhos que se doaram a investigar a temática por nós apresentada se situam na área da saúde. Deste modo, estas investigações não problematizam a responsabilidade da instituição escolar pública e gratuita no processo de viabilização e garantia da permanência às jovens mães. Alguns estudos apontam que a escola tem como função orientar as alunas acerca da prevenção contra as doenças sexualmente transmissíveis e a gravidez indesejada sem, contudo, considerar a maternidade como uma "escolha deliberada" na vida destas mulheres.

Dagmar Meyer (2003) adverte para a existência de uma série de enunciados que delegam à mãe o papel de zelar sozinha pelo desenvolvimento cognitivo, afetivo e físico do feto e da criança após o seu nascimento; estes discursos também impõe à mãe formas de se relacionar e cuidar da criança que, "apesar das inovações tecnológicas e das conquistas dos movimentos feministas, transformaram o exercício da maternidade, na contemporaneidade, em uma tarefa extremamente difícil de abrangente." (MEYER, 2003, p. 38). Esta perspectiva mostra uma lacuna nos estudos que vem sendo feitos sobre evasão escolar e gravidez na adolescência, uma vez que a evasão não tem como causa, exclusivamente, as questões sociais e econômicas, mas também a forma como esse papel social vem sendo imputado às jovens mães que se encontram em idade escolar.

É possível e óbvio concluir, a partir dos estudos por nós empreendidos, e pelos resultados coletados até aqui, que a evasão é fruto de uma série de elementos dificultadores, tais como: conciliação entre horário de aulas e cuidados com o bebê; preconceito decorrente da gravidez na adolescência; questões socioeconômicas que motivam a jovem mãe a se inserir precocemente no mercado de trabalho informal, etc. Estas ocorrências acabam por retirar da aluna-mãe a 
possibilidade de frequentar a escola e, por conseguinte, de concluir, com êxito e qualidade, a educação básica.

\section{CONCLUSÃO}

Concluímos, através das pesquisas por nós analisadas que, apesar de a evasão escolar ser um fenômeno de grande impacto na área da Educação, há um considerável número de pesquisas que o estudam na área da saúde e, por conseguinte, veem a gravidez na adolescência apenas como um "problema de saúde pública", ou ainda, como um "problema social". Não estamos contrariando estas evidências que foram perfeitamente comprovadas e discutidas pelas investigações supracitadas. Pontuamos que é necessário compreender a maternidade enquanto um papel social atribuído aos sujeitos do sexo/gênero feminino e, para analisar uma categoria tão complexa, é preciso levar em consideração as subjetividades e a autonomia das jovens mães em experienciarem a maternidade de uma forma mais positiva e menos contrita.

Acreditamos que os estudos na área da Educação ainda são tímidos e insuficientes para apontarem soluções ou caminhos para que a escola, enquanto uma instituição que resguarda um importante direito humano fundamental, que é o direito a uma educação de qualidade, tome providências efetivas para incluir as jovens-alunas de forma eficiente e equânime. Estas providências são fundamentais, visto que somente a partir delas as jovens mães poderão concluir seus estudos, de modo qualitativo, na educação básica.

\section{REFERÊNCIAS}

AVILA, I. T. L. A reincidência da gravidez na adolescência e a evasão escolar. 2015. 114, [50] f. Dissertação (mestrado) - Universidade Estadual Paulista Júlio de Mesquita Filho, Faculdade de Ciências e Letras (Campus de Araraquara), 2015.

FAVERO, M. H..; MELLO, R. M. Adolescência, maternidade e vida escolar: a difícil conciliação de papéis. Psicologia: Teoria e pesquisa, v.13, n. 1, p. 131-137. jan./abr. 1997.

MEYER, D. E. E. Educação, saúde e modos de inscrever uma forma de maternidade nos corpos femininos. Movimento. Porto Alegre. Vol. 9, n. 3 (set./dez. 2003), p. 33-58, 2003.

MOREIRA, L. E.; NARDI, H. C. Mãe é tudo igual? Enunciados produzindo maternidade (s) contemporânea (s). Estudos Feministas, p. 569-594, 2009. https://doi.org/10.1590/S0104$\underline{026 \times 2009000200015}$

PADILHA, M. Angélica Silveira. As Representações Sociais da Evasão Escolar para Mães Adolescentes: Contribuição para a Enfermagem. 2011. 92 f. Dissertação (Mestrado) - Programa de Pós-Graduação em Enfermagem. Universidade Federal de Pelotas, Pelotas.

RIBEIRO, K. R. Estratégias para o enfrentamento da evasão escolar de mães e grávidas adolescentes no município de Campos dos Goytacazes. 2016. 97 f. Tese (Doutorado) - Curso de Cognição e Linguagem, Universidade Estadual do Norte Fluminense "Darcy Ribeiro" UENF, Campos dos Goytacazes, 2016.

ROMANOWSKI, J. P.; ENS, R. T. As pesquisas denominadas do tipo" Estado da Arte. Revista Diálogo Educacional, v. 6, n. 19, 2006. 
SILVA, K. C. O. Trajetória escolar de jovens com experiência de gravidez na adolescência. Dissertação (mestrado) - Programa de Mestrado em Ciências e Saúde, Universidade Federal do Piauí, Teresina-PI, 2011.

SOUSA, C. R. M. Apoio social e evasão escolar em gestantes adolescentes assistidas na estratégia de saúde da família do município de Sobral - Ceará. 2013. 109 f. Dissertação (Mestrado em Saúde da Família) - Campus de Sobral, Universidade Federal do Ceará, Sobral, 2013.

SOUZA, M. C. A valorização do desejo feminino como via de inclusão escolar da aluna grávida e puérpera: um estudo a partir da filosofia e psicanálise. 2014. 117 f. Dissertação (Mestrado) Programa de Pós-Graduação em Educação Física do Centro de Educação Física e Desportos da Universidade Federal do Espírito Santo, Vitória.

TOKARNIA, M. Estudo mostra que 1,3 milhão de jovens de 15 a 17 anos abandonam a escola. Agência Brasil. Brasília: 2016. Disponível em: <http://agenciabrasil.ebc.com.br/ educacao/noticia/2016-02/13-milhao-de-jovens-entre-15-e-17-anos-abandonamescoladiz estudo> Acesso em: 07 mai. 2018. 